\title{
A INCLUSÃO DA PESQUISA NO ENSINO MÉDIO DA ESCOLA PÚBLICA: UMA INTRODUÇÃO À PESQUISA SOBRE METODOLOGIAS ATIVAS
}

\author{
THE INCLUSION OF RESEARCH IN PUBLIC SCHOOL HIGH \\ SCHOOL: AN INTRODUCTION TO RESEARCH ON ACTIVE \\ METHODOLOGIES
}

Isadora Oro Brocardo ${ }^{1}$ Julia Matte de Carli ${ }^{2}$ Mateus Mota Loiola Coutinho ${ }^{3}$

Carina Merkle Lingnau ${ }^{4}$

\section{RESUMO}

Este artigo é uma investigação que fez parte do projeto de pesquisa sobre metodologias ativas e o discurso na Universidade Tecnológica Federal do Paraná, campus Francisco Beltrão (UTFPR-FB). Esta pesquisa foi desenvolvida por bolsistas de ensino médio e acadêmicos de graduação da UTFPR-FB. O objetivo do trabalho é refletir sobre a relação entre práticas de metodologias ativas no primeiro ano do ensino médio do Colégio Estadual Dr. Eduardo Virmond Suplicy e o discurso foucaultiano (FOUCAULT, 2009). Para fins metodológicos utilizamos pesquisa bibliográfica, documental e a análise do discurso em Michel Foucault. Como resultados verificamos que as práticas das metodologias ativas estiveram presentes em momentos específicos da experiência de ensino médio das bolsistas. Além disso, durante a pesquisa as pesquisadoras utilizaram a plataforma google sala de aula, assim como o aplicativo whatsapp, o que proporcionou a vivência das metodologias ativas no decorrer da investigação. Essas práticas foram relacionadas às verdades produzidas através dos discursos que circulam nos ambientes educacionais.

Palavras-chave: discurso; educação; ensino.

\begin{abstract}
Este artículo es una investigación que formó parte del proyecto de investigación sobre metodologías activas y discurso en la Universidad Tecnológica Federal de Paraná, campus Francisco Beltrão (UTFPR-FB). Esta investigación fue desarrollada por becarios de secundaria y académicos universitarios de UTFPR-FB. El objetivo del trabajo es reflexionar sobre la relación entre las prácticas de metodologías activas en el primer año de secundaria en el Colegio Estadual Colégio Dr. Eduardo Virmond Suplicy y el discurso de Foucault (FOUCAULT, 2009). Para fines metodológicos, utilizamos la investigación bibliográfica, documental y el análisis del discurso de Michel Foucault. Como resultado, verificamos que las prácticas de las metodologías activas estaban presentes en momentos específicos de la
\end{abstract}

\footnotetext{
${ }^{1}$ Aluna de ensino médio no Colégio Estadual Dr. Eduardo Virmond Suplicy, Francisco Beltrão, PR. Email: isadora.obrocardo@ gmail.com. Orcid: https://orcid.org/0000-0003-0967-8072. Link do lattes: http://lattes.cnpq.br/5318839626390247.

2 Aluna de ensino médio no Colégio Estadual Dr. Eduardo Virmond Suplicy, Francisco Beltrão, PR. Email: edudecarli70@gmail.com. Orcid: https://orcid.org/0000-0002-7622-775X Link do lattes: http://lattes.cnpq.br/3758976071975336.

3 Aluno de graduação no curso de Engenharia de Alimentos da UTFPR-FB, bolsista da Fundação Araucária, Email: mateuscoutinho@alunos.utfpr.edu.br Orcid: https://orcid.org/00000001-7990-1052, Link do lattes: http://lattes.cnpq.br/3342387092788080.

${ }^{4}$ Graduada em Letras, Mestra em Educação, Doutora em Letras, professora da UTFPR-FB e pós-graduação da UNIOESTE-FB. E-mail: carinadebeltrao@gmail.com. Orcid: https://orcid.org/0000-0002-8469-3961 Link do lattes: http://lattes.cnpq.br/2891086165049465.
} 
experiencia de la escuela secundaria de los becarios. Además, durante la investigación, los investigadores utilizaron la plataforma Google aula, así como la aplicación WhatsApp, que proporcionó la experiencia de las metodologías activas durante la investigación. Estas prácticas estaban relacionadas con las verdades producidas a través de los discursos que circulan en entornos educativos.

Palabras clave: discurso; educación; enseñando.

\section{INTRODUÇÃO}

Este trabalho tem como temática as metodologias ativas, projetos de estudo em que temos alunos que participam da construção de seu próprio conhecimento com ou sem o apoio de novas tecnologias, com ou sem professor - além do mais, quem nunca quis que uma aula fosse mais dinâmica, mas diferenciada do que as outras? Assim, embasados na teoria foucaultiana, a prática deste projeto que envolve a bolsa de pesquisa do Conselho Nacional de Desenvolvimento Científico e Tecnológico, modalidade Ensino Médio (CNPq-EM) e a bolsa da Fundação Araucária, tem como objetivo entender essa relação entre o discurso a partir da visão foucaultiana e as metodologias ativas.

Esta pesquisa foi desenvolvida entre o segundo semestre de 2019 e o primeiro semestre de 2020 no Colégio Estadual Dr. Eduardo Virmond Suplicy e Universidade Tecnológica Federal do Paraná, campus Francisco Beltrão (UTFPR-FB), entre o primeiro e o segundo ano do Ensino Médio e graduação da UTFPR-FB. A oportunidade de ser bolsista do CNPq se apresentou através da Universidade Tecnológica Federal do Paraná, campus Francisco Beltrão (UTFPR-FB), modalidade de bolsa de pesquisa ensino médio oferecida pelo $\mathrm{CNPq}$, órgão de apoio à pesquisa brasileira.

O fato de existir a inserção da pesquisa no ensino médio auxilia na formação dos alunos, além de fortalecer a autoconfiança para os demais trabalhos escolares. No sentido de compartilhar esta investigação, dividimos este texto nas seguintes seções: metodologias ativas, fundamentação teórica, resultados \& discussões, conclusões e referências.

\section{METODOLOGIAS ATIVAS}

As metodologias ativas estão presentes dentro das mais diversas áreas do ensino a fim de auxiliar o desenvolvimento de um pensamento crítico, a visão e tomada de decisões de futuros profissionais.

Segundo Borges e Alencar (2014, p.120) “a utilização dessas metodologias pode favorecer a autonomia do educando, despertando a curiosidade, estimulando tomadas de decisões individuais e coletivas, advindos das atividades essenciais da prática social e em contextos do estudante". 
Apesar das metodologias ativas auxiliarem na formação dos discentes, encontramos ainda diferentes interpretações do seu alcance e significado. Segundo Moran (2019), dentro do ensino existem diversos entendimentos a respeito das atividades descritas como metodologias ativas, alguns entendem simplesmente como abordagens diferentes para envolver e incentivar a participação dos alunos como aulas invertidas, e projetos. Outra parcela dos docentes enxerga as metodologias ativas como atividades de maior complexidade, investimento e que envolva uma integração maior entre as diversas áreas do conhecimento onde ele cita como exemplo "salas de aula adaptadas, projetos integradores, como o STEAM ${ }^{1}$ que articulam Ciências, Matemática, Engenharia, Artes e Tecnologias”. (MORAN, 2019, p.1).

\section{FUNDAMENTAÇÃO TEÓRICA}

Para a fundamentação deste trabalho foram lidos vários artigos científicos sobre o tópico de metodologias ativas, o livro Foucault Para Principiantes, e Pedagogia da Autonomia.

Deste modo, Fillingham (2004) em seu livro Foucault para principiantes discute vários livros e teorias de Michel Foucault, como por exemplo, a origem dos nossos valores e ideias, que podem ser facilmente aplicadas nas redes de ensino atuais dos colégios brasileiros em que é imposto um horário de chegada e saída aos estudantes, independente se todos os alunos conseguem ou não atender a esse horário com facilidade. Fillingham (2004) também apresenta os pensamentos de Foucault em que trata das regras que são impostas na sociedade diariamente, e como elas nunca são questionadas.

Fillingham (2004) também comenta sobre os conceitos de norma e anormal, discutidos por Foucault, questionando quem impôs essa ideia. Esta discussão encaminha o leitor para o século XVIII, na Revolução Francesa, onde questionamentos eram reprimidos e pessoas com ideais divergentes eram consideradas loucas.

Esta teoria pode ser aplicada também na nossa sociedade atual, pois muitas vezes pessoas que têm ideias impopulares são rotuladas de anormais e consideradas uma anomalia em nossa sociedade.

Outro fator citado por Fillingham (2004) é a evolução da medicina, sobre como séculos atrás as doenças eram diagnosticadas com base no exterior do corpo, e como ao passar dos anos, com o método de dissecação de corpos, o conhecimento anatômico ficou melhor, e como a partir daí esta profissão passou a ser muito requisitada, fato que ocorre até hoje.

\footnotetext{
${ }^{1}$ STEAM - (Science, Technology, Engineering, Arts and Mathematics) - em português a sigla significa Ciência, Tecnologia, Engenharia, Artes e Matemática.
} 
Já Freire (1996) critica as formas de ensino tradicionais e os professores autoritários, e defende uma igualdade entre o educador e o aluno. Ele apresenta a ideia de que o professor deve estimular o estudante a pensar por si mesmo, na tentativa de aprimorar seu senso crítico.

Freire (1996) comenta que os educadores precisam saber que ensinar não é transferir conhecimento, mas criar as possibilidades para a sua própria produção ou a sua construção, ou seja, que os professores devem aceitar questionamentos, curiosidades e inibições dos alunos, para que eles consigam realmente aprender o estudo abordado, também mostra como os professores não devem se preocupar apenas em apresentar a teoria de uma forma esteticamente apresentável, pois devem levar em consideração que o aprendizado também se dá por meio da prática e do uso de metodologias ativas.

Neste livro Freire apresenta a ideia de que o há muitas coisas além de apenas "formar" o aluno, e que o professor deve se preocupar mais com o aprimoramento do conhecimento do estudante.

Freire (1996) também argumenta que a causa da falha em nosso sistema educacional é o uso de metodologias ultrapassadas, que não condiz com os seres inovadores e criativos que são os jovens atualmente. Como estudantes do ensino médio e universitário podemos afirmar que esta teoria pode ser facilmente comprovada nas redes de ensino, em que as aulas são monopolizadas pela metodologia expositiva. Esta forma de ensino por sua vez, pode ser considerada ultrapassada, pois atualmente há várias outras formas de aprendizado que se mostrariam muito mais eficientes, um exemplo seria o uso das metodologias de projetos, envolvendo objetos de nosso cotidiano como celulares, computadores etc.

No decorrer desta pesquisa foram lidos vários artigos, como por exemplo o Metodologias ativas nas aulas de Geografia no Ensino Médio como estímulo do protagonismo juvenil (PEREIRA; KUENZER; TEIXEIRA, 2019). Neste artigo, os autores descrevem como a inserção da tecnologia melhorou o desempenho e o entendimento dos alunos quanto ao conteúdo de Geografia. A experiência apresentada teve a participação de cerca de 60 estudantes, e foi usada a metodologia da sala de aula invertida. O resultado do experimento na respectiva escola foi positivo, pois os alunos se transformaram em protagonistas de seu próprio ensino e isso os motivou a aprender. Porém, para esta metodologia funcionar é necessário o acesso às tecnologias, como computadores ou celulares, recursos que nem todas as instituições de ensino conseguem oferecer.

Em outro exemplo de metodologia, apresentada em um artigo escrito por Fernandes (2018), os alunos são incentivados a produzir seu próprio livro didático, seguindo a ideia do protagonismo do estudante. 
Este experimento tinha como objetivo introduzir um jeito mais fácil de aprender física, pois em teoria, com o uso de tecnologias para a produção do material, o aluno se sentiria mais confortável, pois os meios eletrônicos estão muito presentes em seu cotidiano. Porém, a experiência deve um resultado contrário ao que era previsto, pois os estudantes não tinham domínio de programas como Word, Excel ou Power Point, quesitos que eram obrigatórios para a produção de um livro didático. Esta realidade está presente em várias outras turmas também, pois não há uma disciplina destinada à informática, e muitos alunos não têm acesso a computadores. Esta metodologia provou, de certa forma, como os jovens têm um conhecimento grande de aplicativos como Instagram, Facebook, Youtube, Whatsapp, , porém possuem apenas um conhecimento básico sobre os programas do pacote Office.

As metodologias ativas são um meio mais fácil para um melhor aprendizado dos alunos, que podem ser utilizadas de formas diversas, desde trabalhos em grupos até trabalhos com o apoio de tecnologias, desde a utilização de celulares a computadores providos pela escola ou não.

Um dos maiores problemas dessas metodologias, é que vários professores, seguindo suas próprias experiências com suas salas de aula, não acham que valha a pena utilizar esses meios de aprendizagem. Como alunos, reconhecemos quantos alunos não fazem todos os pedidos dos professores, então isso se tornaria um grande problema na hora de fazer os exercícios e os projetos orientados pelos professores. Entretanto, as metodologias ativas não precisam necessariamente vir do professor, os alunos podem dar ideias para eles, sugerindo diversas formas em que poderiam exercer sua criatividade e inteligência de uma forma mais divertida e leve para todos os envolvidos.

Para fazer com que os alunos construam o conhecimento, os professores devem fazer com que eles interajam, podendo assim compartilhar e relatar suas descobertas junto aos colegas de sala, ou até mesmo de salas diferentes. O sentido por trás das metodologias ativas é não dar as respostas prontas para os alunos, mas deixar que eles cheguem as suas próprias conclusões e façam suas próprias perguntas e pesquisas, internalizando assim o conhecimento que em suas mentes.

Para que esta forma de aprendizado seja bem utilizada, ela não poderá acontecer de modo improvisado. O professor deverá se ater aos fatores importantes em sua sala de aula, lembrando que por mais que uma metodologia tenha funcionado com um grupo de alunos, essa mesma metodologia poderá não ser suficiente, necessária ou divertida para um outro grupo de alunos. O professor terá que levar em conta os interesses, curiosidades e a forma de trabalhar com determinado grupo. 
Para Moran $(2017 ; 2020)$ o melhor funcionamento das metodologias ativas se dá através de uma aula planejada, não apenas com a matéria, mas levando em conta a interação professor e aluno, em que o aluno será capaz de mostrar seus próprios saberes e poderá tirar suas próprias dúvidas. As mudanças não vêm só dos professores, mas também dos alunos e das instituições.

Moran $(2017 ; 2020)$ ainda apresenta a importância de relacionar os conteúdos com a vida do aluno, aos fatos cotidianos e aos projetos. Aproveitando tudo que é importante para o aluno e construir o conhecimento a partir disso. Além disso, o conteúdo em vídeo também pode ser um meio de comunicação imediata com o aluno, tanto para ele se inteirar do conhecimento como para produzi-lo. Como resultado, o professor não irá focar no conteúdo, mas sim no aprendizado individual de cada aluno.

Como outro exemplo de metodologias ativas, podemos observar as utilizadas para o ensino de inglês no Japão (AMRAN; YOKOYAMA; NISHINO, 2016), em que foram realizadas depois de ser anunciado que o inglês seria uma aula regular para as escolas japonesas. Foram feitos trabalhos em grupo e questionários, utilizando a tecnologia como meio de produção. Foram realizadas atividades utilizando o Google Docs e Google Forms, em que os estudantes faziam o questionário e se comunicavam com outros grupos, via e-mail, links, chats, e/ou redes sociais. Os resultados do questionário mostraram que os alunos preferiam utilizar a tecnologia, além de preferirem terem aulas em grupo.

Temos uma dificuldade muito grande na questão de avanço na educação, várias escolas e universidades brasileiras utilizam sistemas mais interativos, contudo, o ensino e o aprendizado funcionam de forma mais lenta do que é esperado. Segundo Moran $(2017 ; 2020)$, quando falando sobre o avanço da educação, existem vários fatores que explicam a lentidão, como nossas políticas públicas sem continuidade e consistência, ou a falta de atração dos docentes por conta dos baixos salários e a valorização profissional. As condições estruturais de nossa sociedade são essenciais para uma transformação.

Para conseguirmos embasar as metodologias ativas nos ensinamentos de Foucault (1984), precisamos compreender algumas noções de conceitos como saber e poder. Foucault sempre quis entender o saber dos seres humanos e o poder exercido sobre os seres humanos. Para se ter poder precisa ter conhecimento, assim precisa saber. O saber para Foucault (1984) é controlado por uma minoria da sociedade capaz de criar verdades absolutas.

Com isso, começamos a pensar o que é normal e o que é anormal na nossa sociedade. Damos o poder para a minoria poder criar e desfazer as verdades que conhecemos, impor o que devemos fazer ou não para que tenhamos bons resultados em uma sociedade. Assim, se nos atrasamos, se dizemos algo ou até mesmo se vemos algo na internet ou postamos algo que 
a sociedade (ou a minoria da sociedade impôs) isso pode ser considerado como errado ou feio. É como se a minoria estivesse nos vigiando e castigando por qualquer deslize que dermos.

Sem percebemos, deixamos que a minoria que controla o saber e o poder da sociedade, no controle com o próprio poder que demos a ela, sem discutir a anormalidade que isso gera na sociedade, nem parando para pensar nas tantas "verdades" que foram impostas sobre nós que nem mesmo nos importamos em refletir.

A partir do final do século XVII, depois do maior aprofundamento no estudo do corpo humano e da descoberta dos corpos dóceis por Foucault, onde este mesmo diz que são corpos dóceis aqueles que podem ser submetidos, utilizados, transformados e aperfeiçoados, o corpo passa a ser submetido a uma nova técnica: a disciplina. Esta disciplina tem como função não só o aumento de suas habilidades, mas também procura fazer com que os corpos se tornem mais obedientes, assim, fazendo-os úteis para a sociedade.

Várias instituições praticam essa disciplina, como por exemplo: internatos, quartéis, e principalmente, a escola. Assim, a escola passa a ser, além de um lugar de aprendizado, uma instituição de hierarquização e vigilância constante. Nesse sentido, encaminhamos o texto para os resultados e discussões do trabalho.

\section{RESULTADOS \& DISCUSSÕES}

Atualmente a importância do saber cresce de forma acelerada e para facilitar isso, podemos usar as metodologias ativas, tanto para explicá-lo quanto para tê-lo. Quanto mais fácil é para o aluno adquirir o saber, mais facilmente será para entender as anormalidades da sociedade, levando em conta que não somos nós que decidimos ou mudamos isto.

Assim, vemos que para não sermos controlados pelo poder social, precisamos ter mais conhecimento, e o lugar ideal e com mais fácil acesso é a escola, com a ajuda dos professores e com a vontade dos alunos.

Quanto mais nós sabemos como a sociedade funciona e nos coloca em determinadas situações, mais precisamos saber como nos proteger, e mais importante, precisamos ter poder para isso, mas como nos proteger contra as verdades criadas? Para isso, nós precisamos ter o nosso próprio poder para mostrarmos quais são as outras possibilidades de verdade. Contudo, nada disso é possível se o aluno não tem vontade própria para se questionar e procurar suas próprias respostas.

O professor pode impulsionar o aluno, mas ele não irá fazer com que ele aprenda se ele não quiser. Por mais que exista um número considerável de alunos que queiram aprender e entender a sociedade, não só as matérias propostas pela escola, existe um número muito maior que não se dedica ou se importa por nenhum contexto educacional. 
A sala de aula, segundo Moran (2017; 2020) é um lugar de ampliação, desenvolvimento e debate, em que, depois de ter feito pesquisas por si próprio, pode vir a ganhar um conhecimento mais amplo, junto ao professor.

Nesse caso especificamos neste momento o resultado do que foi por nós vivenciado ao longo do ano de 2019, em que várias metodologias foram aplicadas no primeiro ano "A" do Colégio Estadual Dr. Eduardo Virmond Suplicy, Francisco Beltrão, PR. Entre elas podemos citar o experimento da vela (Figura 1) que teve por objetivo facilitar a compreensão sobre a função afim, o que se revelou efetivo para o grupo, uma vez que a partir da relação concreta da prática e abstrata teórica os alunos puderam exercitar a noção de aplicação da função.

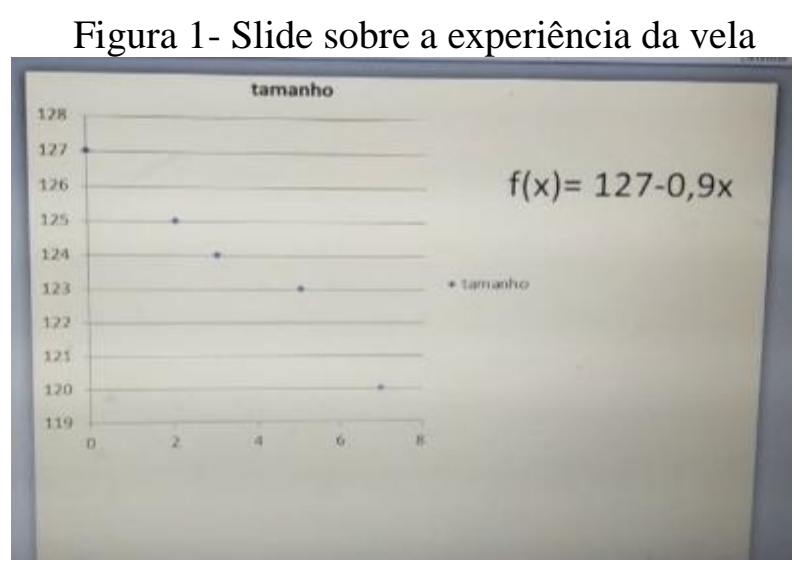

Fonte: Acervo pessoal.

Outro resultado do uso das metodologias ativas no Colégio foi a elaboração do mapa dos fusos horários em uma lata de refrigerante (Figura 2) e o globo terrestre em uma bola de isopor (Figura 3). Assim como em estudo realizado por Pereira, Kuenzer e Teixeira (2019), este projeto também ocorreu durante as aulas de Geografia. Nesse caso, o fato de usarmos o conhecimento teórico na confecção dos recursos de aprendizagem envolveu o conteúdo no cotidiano a partir do uso da lata de refrigerante e da bola de isopor, em que foi possível a realização de discussões sobre geopolítica, reciclagem e o fuso horário e o mapa mundi, como tema gerador.

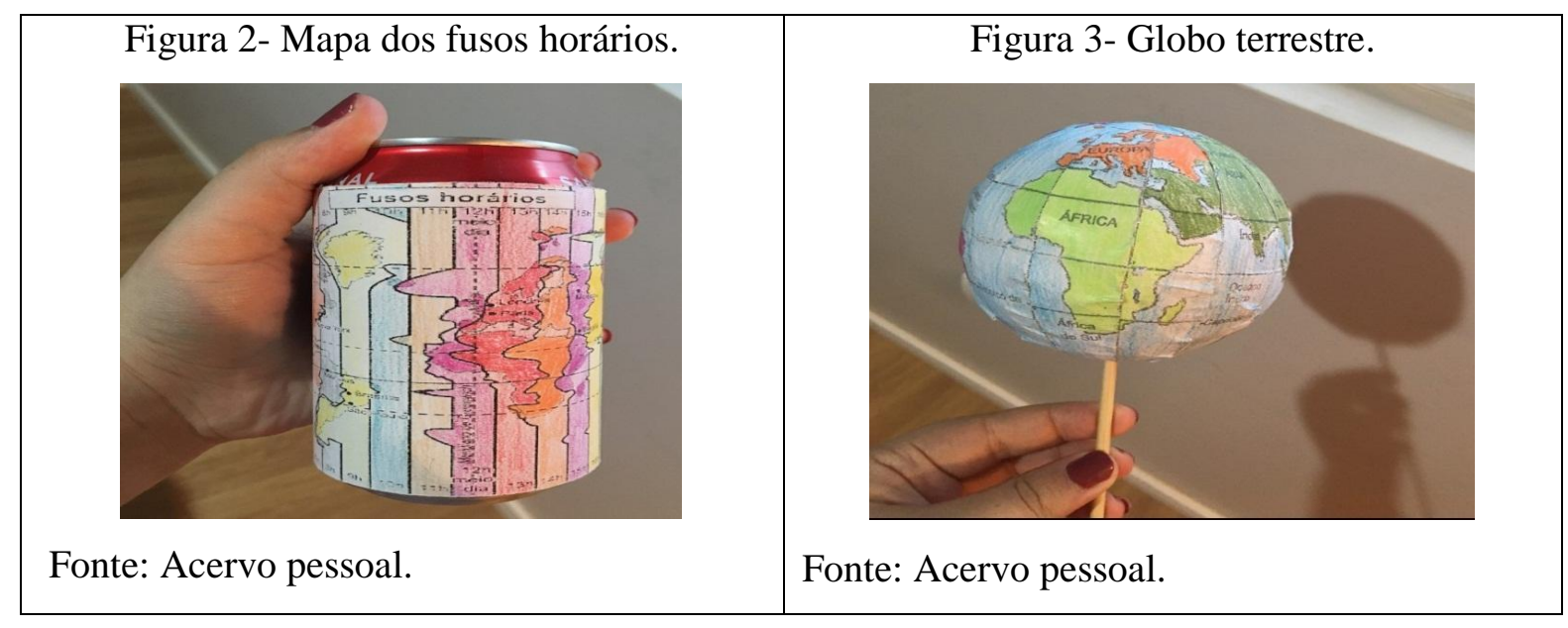


Além disso, a turma se apropriou de conteúdos históricos quando elaborou um templo grego feito com materiais recicláveis (Figura 4). Desse modo, constatamos que esta metodologia de projetos pode ser observada também no artigo escrito por Buss e Mackedanz (2017) em que mostram uma comparação entre as metodologias expositivas e as de projetos. Nesse caso, empreender esforços na aplicação do conteúdo foi bem mais eficiente do que apenas acessar os materiais de forma expositiva.

Figura 4 - Templo grego.

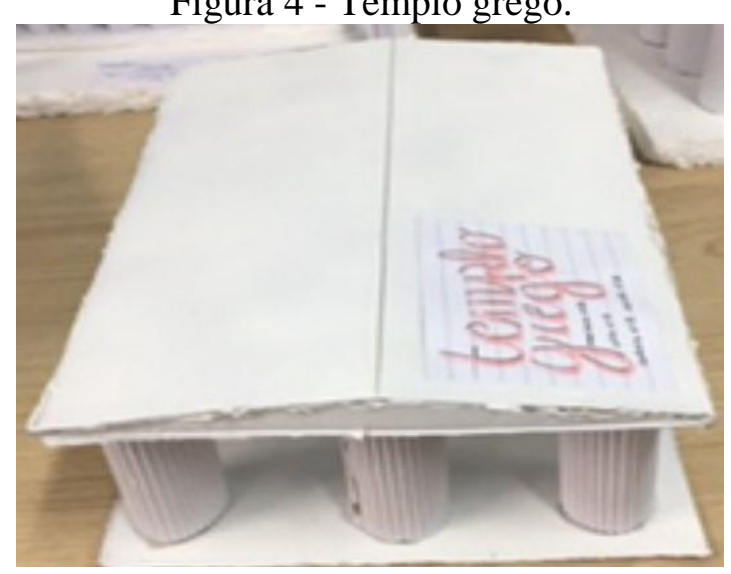

Fonte: Acervo pessoal.

Assim, de forma metalinguística em relação à temática pesquisada, os momentos de orientação fizeram uso das metodologias ativas em momentos que oportunizaram o uso de plataformas (Figura 5, 6 e 7) como google sala de aula para adicionar atividades, fazer comentários, postar dúvidas e discutir assuntos. Sobre isso, retomamos Freire (1996) quando comenta em sua obra sobre os professores autoritários e conservadores, e sobre como a relação de respeito entre aluno e professor é importante. Ele apresenta vários argumentos a favor de um ensino mais democrático entre o educador e o estudante, pois todos ainda temos muito a aprender.

Figura 5 - Google sala de aula.

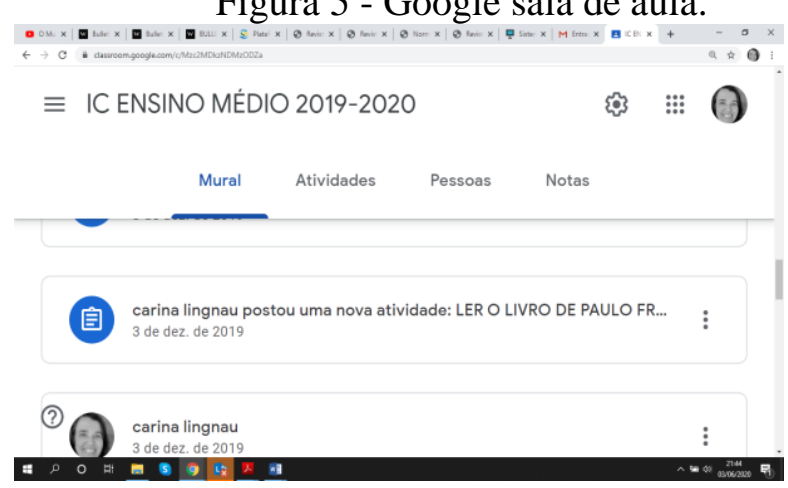

Fonte: https://classroom.google.com/c/Mzc2MDkzNDMzODZa 
Figura 6 - Postagem google sala de aula.

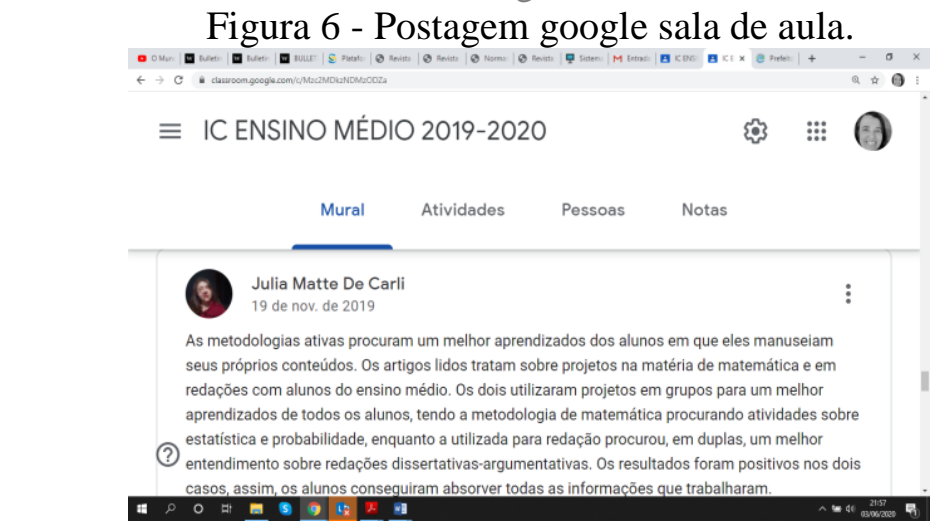

Fonte: https://classroom.google.com/c/Mzc2MDkzNDMzODZa

Figura 7 - Leituras e postagens.

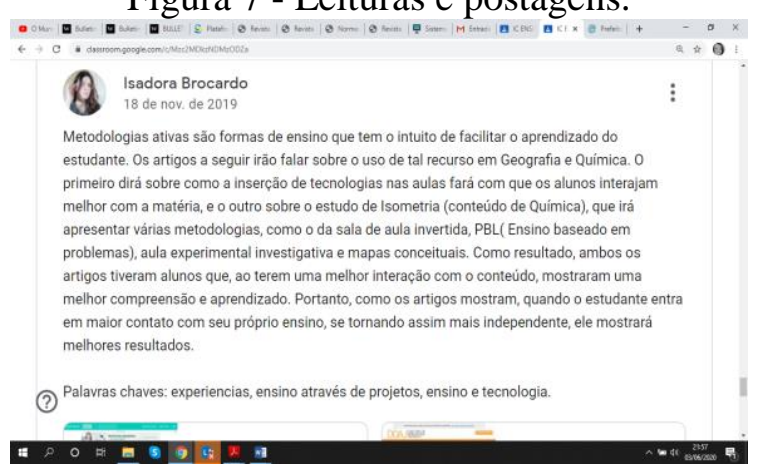

Fonte: https://classroom.google.com/c/Mzc2MDkzNDMzODZa

Nesta relação, associamos Fillingham (2004) em seu livro, quando cita em um dos capítulos como Freud achava que tudo dependia da relação doutor-paciente, e nas redes de ensino essa ideia pode ser aplicada, pois como pode ser visto nas metodologias aplicadas no colégio Suplicy, as atividades tiveram maior sucesso quando os alunos tinham uma boa relação com o professor.

Verificamos então que os experimentos efetuados no Suplicy tiveram como resultado um aprendizado melhor da parte dos alunos, pois assim eles interagiam mais diretamente com o conteúdo e com seu próprio ensino. Pôde ser notado também que nem todas as metodologias tiveram o resultado esperado, pois houve alguns momentos em que alguns estudantes não se comprometiam ao projeto, e assim atrapalhavam os outros por meio de conversas.

\section{CONSIDERAÇÕES FINAIS}

Observamos que as metodologias ativas, quando relacionadas às necessidades do aluno (além de sua pequena diversão), irão ajudá-lo social e academicamente, deixando que acesse o conhecimento da sociedade a sua volta e que consiga confrontá-la. Levando em conta Foucault (1984) nos dias de hoje, ele não só ajudaria os estudantes em suas escolas, mas também em suas vidas profissionais e pessoais. 
Depois de toda a pesquisa feita sobre as metodologias ativas dentro e fora da escola, verificamos que para um melhor ensinamento dos educandos, além de um maior aprendizado dos educadores, as escolas deveriam implantar mais metodologias ativas. Segundo Freire (1996), o nosso sistema educacional está falho pela falta de metodologias ativas, e pela abundância de aulas expositivas.

A partir da realização destas atividades pôde ser percebido que os alunos conseguem compreender o conteúdo de uma forma mais fácil quando há o uso de metodologias ativas, isso ocorre devido ao fato de que o ensino é muito monopolizado pela aula expositiva, deixando os alunos desmotivados, portanto, ao inserir uma forma diferente de aprendizado, o estudante tende a ser mais receptivo com o estudo abordado.

Isso pôde ser visto a partir dos artigos lidos e das metodologias aplicadas em sala. Inseridos no contexto da educação, foi possível notar como algumas metodologias ajudam no entendimento dos conteúdos, assim como outras infelizmente não podem ser realizadas por falta de recursos, entre outras causas. Muitas das ideias apresentadas em alguns dos artigos lidos poderiam ser facilmente aplicadas no colégio Suplicy, e consideramos que trariam resultados melhores do que as tradicionais aulas expositivas.

\section{REFERÊNCIAS}

AMRAN, R; YOKOYAMA, F; NISHINO, K. Development of active learning methods of English in Japanese high schools to support student activities in group discussions. Procedia Computer Science, 2016; p. 1472-1478. Disponível em: https://www.sciencedirect.com/science/article/pii/S1877050916320038. Acesso em: 27 abr. 2021.

BORGES, T.S.; ALENCAR, G. "Metodologias ativas na promoção da formação crítica do estudante: o uso das metodologias ativas como recurso didático na formação crítica do estudante do ensino superior". Cairu em Revista, Jul/Ago. Ano 03, nº 04, 2014.

BUSS, C.S; MACKEDANZ, L.F. O ensino através de projetos como metodologia ativa de ensino e de aprendizagem. Revista Thema, Pelotas, v.14, n. 3, 2017.

FERNANDES, R.I. et al. Metodologias ativas aplicadas no Ensino de Física para o Ensino Médio. Revista Tecnologias na Educação, Curitiba, v.24, n.24, 2018.

FILLINGHAM, L.A. Foucault para principiantes. Buenos Aires: Era Nasciente, 2004.

FOUCAULT, M. A Ordem do Discurso. Aula Inaugural no Collège de France, pronunciada em 2 de dezembro de 1970. 19.ed. São Paulo: Edições Loyola, 2009.

FREIRE, P. Pedagogia da autonomia. São Paulo: Paz e Terra, 1996.

MORAN, J. Entrevista José Moran - Metodologias Ativas, mar 2017. Disponível em: < https://www.youtube.com/watch?v=O4icT4Z8m6Q>. Acesso em: 15 de março de 2020. 
MORAN, J. Por que avançamos tão devagar na Educação? Escola de comunicação e artes universidade de São Paulo (ECA), 2020. disponível em: 〈http://www2.eca.usp.br/moran/wpcontent/uploads/2017/11/devagar.pdf>. Acesso em: 15 de março de 2020.

PEREIRA, A.M.de O.; KUENZER, A. Z.; TEIXEIRA., A. C. Metodologias ativas nas aulas de Geografia no Ensino Médio como estímulo ao protagonismo juvenil. Educação (Santa Maria. online), v. 44, p. 73, 2019.

Artigo Recebido: 29 de março de 2021.

Artigo Aceito: 02 de maio de 2021. 